\title{
Inhaled nitric oxide versus prostacyclin in chronic shunt- induced pulmonary hypertension
}

Pierre Wauthy, MDa

Sophia Abdel Kafi, MD

Wolter J. Mooi, MD, PhD

Robert Naeije, MD, $\mathrm{PhD}^{\mathrm{a}}$

Serge Brimioulle, MD, $\mathrm{PhD}^{\mathrm{c}}$

From the Laboratory of Physiology, ${ }^{a}$ Free University of Brussels, Brussels, Belgium; the Department of Pathology, ${ }^{\text {b }}$ Erasmus University Hospital, Rotterdam, The Netherlands; and the Department of Intensive Care, ${ }^{\mathrm{c}}$ Erasme University Hospital, Brussels, Belgium.

P. Wauthy was supported by the Erasme Foundation (CPM grant). The study was supported by the Belgian Foundation for Cardiac Surgery and by the Belgian Fund for Medical Scientific Research (grant no. 3.4567.00).

Received for publication Nov 27, 2002; revisions requested Feb 20, 2003; revisions received April 26, 2003; accepted for publication July 17, 2003.

Address for reprints: Pierre Wauthy, MD, Département de Chirurgie Cardiaque, $\mathrm{CHU}$ Brugmann, 4, Place Van Gehuchten, B-1020 Brussels, Belgium (E-mail: pierre.wauthy@wanadoo.be).

J Thorac Cardiovasc Surg 2003;126: $1434-41$

Copyright $\odot 2003$ by The American Association for Thoracic Surgery

$0022-5223 / 2003 \$ 30.00+0$

doi:10.1016/S0022-5223(03)01183-8
Objective: Cardiac surgery for congenital heart defects is commonly complicated by shunt-induced chronic pulmonary hypertension and associated acute hypertensive crises. To investigate the effects of vasodilators in chronic and acute pulmonary hypertension, we used the innominate artery to create a growing aortopulmonary shunt in young piglets.

Methods: Pulmonary hemodynamics and right ventricular function and their responses to hypoxia, intravenous prostacyclin, and inhaled nitric oxide were investigated after closure of the shunt by using pulmonary flow-pressure relationships, pulmonary vascular resistance partitioning, pulmonary vascular impedance, and ventriculoarterial coupling expressed as the ratio of right ventricular end-systolic elastance to effective pulmonary arterial elastance.

Results: Shunt-induced pulmonary hypertension was associated with medial hypertrophy of pulmonary arteries, increased resistance, increased elastance, increased wave reflection, and preserved ventriculoarterial coupling. Hypoxic pulmonary vasoconstriction was blunted in the shunt group. Compared with prostacyclin, inhaled nitric oxide was a more effective vasodilator in the shunt group and in hypoxia. Effective pulmonary arterial elastance and right ventricular end-systolic elastance increased in chronic (shunt) and acute (hypoxic) hypertension and decreased with vasodilators, preserving a normal coupling.

Conclusions: A growing aortopulmonary shunt in the young pig is a reliable model of chronic pulmonary hypertension, with medial hypertrophy, increased resistance, and increased elastance. In this model inhaled nitric oxide is a better pulmonary vasodilator than intravenous prostacyclin, with neither drug having a specific inotropic effect, and normal coupling is preserved in chronic and acute pulmonary hypertension.

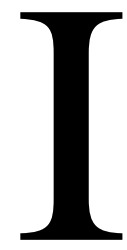

$\mathrm{n}$ congenital heart defects associated with left-to-right shunting, pulmonary hypertension is an important determinant of morbidity and mortality after surgical shunt correction. ${ }^{1}$ In earlier stages of the disease, pulmonary hypertension progressively resolves after the surgical correction. Vascular reactivity, however, remains increased for some days after the operation and can result in life-threatening postoperative hypertensive crises with hypoxemia and right ventricular (RV) failure. ${ }^{1}$ Later in the evolution of the disease, irreversible structural changes are present, and pulmonary hypertension might persist despite surgical correction of the shunt.

Experimental attempts to reproduce the pulmonary hypertension associated with left-to-right shunting have met with variable success. Better results have been obtained after increased pressure and flow than after increased flow only ${ }^{2}$ in pigs than in other species and in newborn than in young or adult animals. ${ }^{3}$ Authors who 
created an 8-mm aortopulmonary shunt in young pigs reported medial hypertrophy and moderate pulmonary hypertension after 3 months. ${ }^{3,4}$ Attempts to generate more hypertension with a 10-mm shunt failed because of acute pulmonary edema and death in all animals. ${ }^{4}$ We therefore tried to obtain more pulmonary hypertension by using a shunt that would grow with the animals.

Pulmonary hypertensive crises might be triggered by hypoxemia, hypercapnia, metabolic acidosis, restlessness, and endotracheal suctioning. ${ }^{1}$ The treatment consists of oxygenation, hyperventilation, sedation, and muscle paralysis. If pulmonary hypertension persists, administration of a vasodilator is recommended. Prostacyclin and inhaled nitric oxide (iNO) are potent drugs selected for vasodilator testing in patients with pulmonary hypertension. ${ }^{5-7}$ Prostacyclin and its analogues have been associated with an increase in cardiac output and a positive inotropic effect, ${ }^{8,9}$ but they cause systemic hypotension and inhibit platelet aggregation. iNO might be a better pulmonary vasodilator after operations for congenital heart defects, ${ }^{10-12}$ but it has been associated with an increase in left atrial pressure and a negative inotropic effect. ${ }^{13,14}$

The aims of the present study were to investigate more completely the changes in pulmonary vessels and the right ventricle that occur in chronic high-pressure high-flow pulmonary hypertension caused by an aortopulmonary shunt and to compare the vasodilating effects of prostacyclin and iNO in acute and chronic shunt-induced pulmonary hypertension.

\section{Methods}

All experiments were conducted in accordance with the "Guide for the Care and Use of Laboratory Animals" and after approval by the Committee on the Care and Use of Animals in Research of the Brussels Free University School of Medicine. Growing pigs were enrolled immediately after weaning from maternal feeding (age 3-4 weeks).

\section{Surgical Procedure}

Animals were premedicated with $20 \mathrm{mg} / \mathrm{kg}$ intramuscular ketamine and $0.1 \mathrm{mg} / \mathrm{kg}$ intramuscular midazolam. After $0.25 \mathrm{mg}$ of intramuscular atropine, anesthesia was induced with $1 \mathrm{mg} / \mathrm{kg}$ intravenous midazolam and $10 \mu \mathrm{g} / \mathrm{kg}$ intravenous fentanyl and maintained with $0.1 \mathrm{mg} \cdot \mathrm{kg}^{-1} \cdot \mathrm{h}^{-1}$ midazolam and 2 to $3 \mu \mathrm{g}$. $\mathrm{kg}^{-1} \cdot \mathrm{h}^{-1}$ fentanyl. Paralysis was obtained with $0.2 \mathrm{mg} \cdot \mathrm{kg}^{-1}$. $\mathrm{h}^{-1}$ intravenous pancuronium bromide. The pigs were ventilated with an inspired oxygen fraction $\left(\mathrm{FiO}_{2}\right)$ of 0.4 , a tidal volume of 15 $\mathrm{mL} / \mathrm{kg}$, and a respiratory rate of 12 breaths $/ \mathrm{min}$. One gram of intravenous cefazolin was given before and 2 hours after the surgical procedure. A thoracotomy was performed through the third intercostal space, and the left innominate artery (diameter, 5-6 $\mathrm{mm}$ ) was dissected and anastomosed to the pulmonary artery (Figure 1). At the end of the procedure, the shunt was either maintained (shunt group, $\mathrm{n}=9$ ) or closed (sham group, $\mathrm{n}=8$ ). The lungs were re-expanded, and pleural air was evacuated before

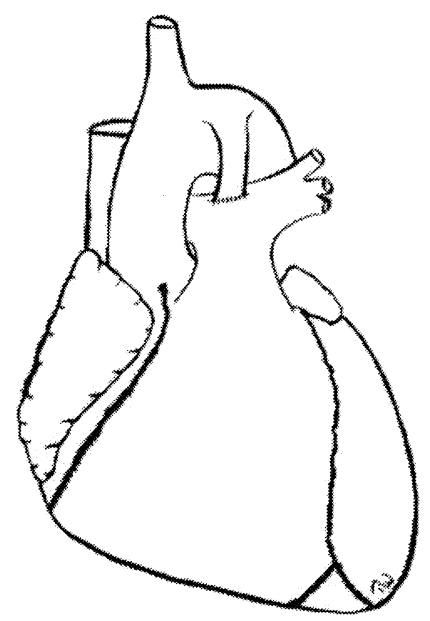

Figure 1. Illustration of the surgical procedure. The left innominate artery is connected to the main pulmonary artery to generate a shunt that will increase over time to induce high-flow, highpressure pulmonary hypertension.

closure of the chest. The piglets were awakened and weaned from mechanical ventilation. They received $5 \mathrm{mg}$ of subcutaneous morphine twice daily for 2 days and $20 \mathrm{mg}$ of intramuscular furosemide to prevent pulmonary edema.

\section{Preparation}

Measurements were done 10 to 12 weeks later ( $77 \pm 3$ days; range, 69-83 days), with the same anesthetic regimen as for the first procedure. Anesthesia and mechanical ventilation were maintained until the end of measurement. Femoral and pulmonary arterial catheters were inserted to monitor pressures, to measure cardiac output by means of thermodilution, and to draw arterial and mixed venous blood. Thoracotomy was performed through the fourth left intercostal space. A micromanometer-tipped catheter (SPC 350; Millar Instrument, Houston, Tex) was introduced in the right ventricle, and a pressure and velocity sensor catheter (SVPC664A, Millar) was introduced in the proximal main pulmonary artery. Micromanometer-derived pressures were processed by using TCB-500 units (Millar), and velocity was processed by using a FM501 flowmeter (Carolina Medical, King, NC). A tourniquet was placed around the inferior vena cava to control cardiac output by reducing venous return. The lungs were fully expanded, pleural air was evacuated, and the chest was tightly closed.

\section{Measurements}

In each set of measurements, cardiac output was measured and velocity and pressure signals were recorded in stable conditions for calculation of pulmonary vascular impedance (PVZ) and RV function after inflation of the pulmonary arterial balloon for calculation of capillary pressure and longitudinal pulmonary vascular resistance partitioning and during vena caval compression for generation of flow-pressure curves. A complete set of measurements was done at baseline in hyperoxia $\left(\mathrm{FiO}_{2}\right.$ of 0.40$)$ and repeated after 10 minutes of ventilation in hypoxia $\left(\mathrm{FiO}_{2}\right.$ of 0.12$)$. After return to hyperoxia and 30 minutes of hemodynamic stabilization, prosta- 
TABLE 1. Baseline hemodynamics and blood gases in piglets in the sham and shunt groups

\begin{tabular}{|c|c|c|c|}
\hline & \multirow{2}{*}{$\begin{array}{c}\text { Sham } \\
\text { Baseline }\end{array}$} & \multicolumn{2}{|c|}{ Shunt } \\
\hline & & $\begin{array}{l}\text { Before } \\
\text { closure }\end{array}$ & Baseline \\
\hline $0, \mathrm{~L} \cdot \mathrm{min}^{-1} \cdot \mathrm{m}^{-2}$ & $3.6 \pm 0.2$ & $3.3 \pm 0.3$ & $2.4 \pm 0.2^{*}$ \\
\hline $\mathrm{HR}$, beats/min & $115 \pm 8$ & $109 \pm 9$ & $126 \pm 14$ \\
\hline Psa, mm Hg & $118 \pm 10$ & $127 \pm 6$ & $121 \pm 6$ \\
\hline Pra, mm Hg & $6 \pm 1$ & $6 \pm 1$ & $7 \pm 1$ \\
\hline Ppa, mm Hg & $26 \pm 1$ & $40 \pm 1^{*}$ & $27 \pm 1^{*}$ \\
\hline $\mathrm{Ppc}, \mathrm{mm} \mathrm{Hg}$ & $13 \pm 1$ & - & $16 \pm 1$ \\
\hline $\mathrm{Pla}, \mathrm{mm} \mathrm{Hg}$ & $7 \pm 1$ & $8 \pm 1$ & $8 \pm 1$ \\
\hline PVRa, \% & $65 \pm 3$ & - & $68 \pm 3$ \\
\hline $\mathrm{pH}_{\mathrm{a}}$ & $7.49 \pm 0.01$ & $7.45 \pm 0.02$ & $7.42 \pm 0.03$ \\
\hline $\mathrm{PaCO}_{2}, \mathrm{~mm} \mathrm{Hg}$ & $39 \pm 2$ & $35 \pm 1$ & $37 \pm 2$ \\
\hline $\mathrm{PVO}_{2}, \mathrm{~mm} \mathrm{Hg}$ & $201 \pm 23$ & $173 \pm 15$ & $176 \pm 15$ \\
\hline $\mathrm{PaO}_{2}, \mathrm{~mm} \mathrm{Hg}$ & $46 \pm 1$ & $42 \pm 4$ & $43 \pm 4$ \\
\hline
\end{tabular}

Values are means $\pm \mathrm{SE}$. $Q$, Flow; $H R$, heart rate; $P s a$, systemic arterial pressure; $P r a$, right atrial pressure; $P p a$, pulmonary arterial pressure; $P p c$, pulmonary capillary pressure; $P l a$, left atrial pressure; $P V R a$, arterial component of pulmonary vascular resistance; $P_{V O_{2}}$, partial pressure of oxygen, mixed venous.

${ }^{*} P<.05$ versus previous column.

cyclin (epoprostenol, Flolan; Glaxo-Smith-Kline, Genval, Belgium) was started and incremented as $2 \mathrm{ng} \cdot \mathrm{kg}^{-1} \cdot \min ^{-1}$ every 10 minutes until side effects appeared (decrease in arterial pressure of $>30 \%$, increase in heart rate of $>30 \%$, or premature beats). Prostacyclin was decreased to the previous dose, and measurements were made again in hyperoxia and in hypoxia. After discontinuation of prostacyclin, return to hyperoxia, and 30 minutes of hemodynamic stabilization, iNO was administered at $40 \mathrm{ppm}$, and measurements were done again in hyperoxia and in hypoxia (iNO was not titrated because the 40-ppm dose yields a maximal vasodilating response without causing side effects).

\section{Data Analysis}

All pressures and the velocity signals were digitized at $200 \mathrm{~Hz}$ and stored on a PC for offline analysis. Velocity was converted to flow by using the thermodilution value and was zeroed at the diastolic zero-flow value. Flow-pressure plots were obtained from 5 beats sampled throughout the flow-reduction maneuver. ${ }^{15}$ Pressures and flow values were submitted to linear correlation analysis $(r>0.95)$ to generate individual regression lines and interpolate pulmonary arterial pressure minus left atrial pressure (Ppa - Pla) values at flows of 1.5 and $3.5 \mathrm{~L} \cdot \min ^{-1} \cdot \mathrm{m}^{-2} \cdot{ }^{15}$ Capillary pressure $(\mathrm{Ppc})$ was computed by means of biexponential fitting of the Ppa decay curve after inflation of the balloon of the pulmonary artery catheter. ${ }^{16}$ The arterial component of resistance was calculated as (Ppa - Ppc)/(Ppa - Pla) and expressed as a percentage. PVZ was calculated from the Fourier series expressions of pressure and flow waves. ${ }^{17}$ From PVZ spectra were derived the $0-\mathrm{Hz}$ impedance modulus or total resistance (Zo), and the characteristic impedance $(\mathrm{Zc})$ was computed as the average of moduli between 2 and 15 Hz. ${ }^{17}$ The pressure wave was separated into forward and backward components, and wave reflection was quantified as the amplitude of the reflected wave (Rampl). ${ }^{18}$ Right ventriculoarterial coupling was computed from RV pressure-volume curves by using a singlebeat method. ${ }^{19}$ The RV contractility was estimated as the slope of the end-systolic pressure-volume relationship (Ees), and the pulmonary effective arterial elastance (Ea) was estimated as the slope of the end-diastolic to end-systolic relationship. ${ }^{20}$ Ventriculoarterial coupling efficiency was defined as the Ees/Ea ratio. ${ }^{21}$

\section{Pathology}

Histologic examination was done by using standard methods. ${ }^{22}$ For each animal, at least 10 blocks of formalin-fixed lung tissue, randomly taken from the central and peripheral areas of the lungs, were paraffin embedded by using standard protocols. Light microscopy was performed without knowledge of the group allocation or hemodynamic data. A hematoxylin-eosin stain and a resorcin-fuchsin stain for elastin were performed on 5- $\mu \mathrm{m}$ thick sections from each block. In each piece 10 small muscular pulmonary arteries of variable diameter (80-200 $\mu \mathrm{m})$ were studied. The medial thickness was measured with an eyepiece micrometer as the distance between the internal and external elastic laminae. Thickness was expressed as a percentage of the external vessel diameter.

\section{Statistical Analysis}

Results are expressed as means \pm SE. Effects of shunt, hypoxia, and vasodilators were assessed by means of repeated-measures analysis of variance and Fisher protected $t$ tests.

\section{Results}

After the operation, all piglets in the shunt group maintained a loud continuous murmur in the left chest that increased during the first week. Two piglets in the shunt group had pulmonary edema after the operation and received additional furosemide; one died, and the other survived. One piglet in the sham group had mediastinitis and died. At the time of measurement, animals in the sham and shunt groups had similar body weights (mean, $21 \mathrm{vs} 20 \mathrm{~kg}$ ). All pigs in the shunt group had a patent shunt that had grown to the size of 9 to $10 \mathrm{~mm}$. The pulmonary/systemic flow ratio determined by means of oximetry was $1.75 \pm 0.07$ (range, 1.36-2.00). After initial measurements, the shunt was closed to correctly evaluate pulmonary vascular resistance and PVZ.

\section{Effects of Shunts}

Before closure of the shunt and after the initial fluid administration reached a left atrial pressure of about $8 \mathrm{~mm} \mathrm{Hg}$, animals in the shunt group had a similar flow but higher Ppa than animals in the sham group (40 $\pm 1 \mathrm{vs} 26 \pm 1 \mathrm{~mm} \mathrm{Hg})$. Other hemodynamic variables were comparable in the 2 groups (Table 1). Closure of the shunt reduced pulmonary blood flow $\left(3.3-2.4 \mathrm{~L} \cdot \mathrm{min}^{-1} \cdot \mathrm{m}^{-2}\right)$ and Ppa in the shunt group but did not affect the distribution of arterial and venous resistances (Table 1). Flow-pressure plots were shifted to higher pressures in the shunt group (Figure 2). All the following data were collected at a similar flow of 2 to 


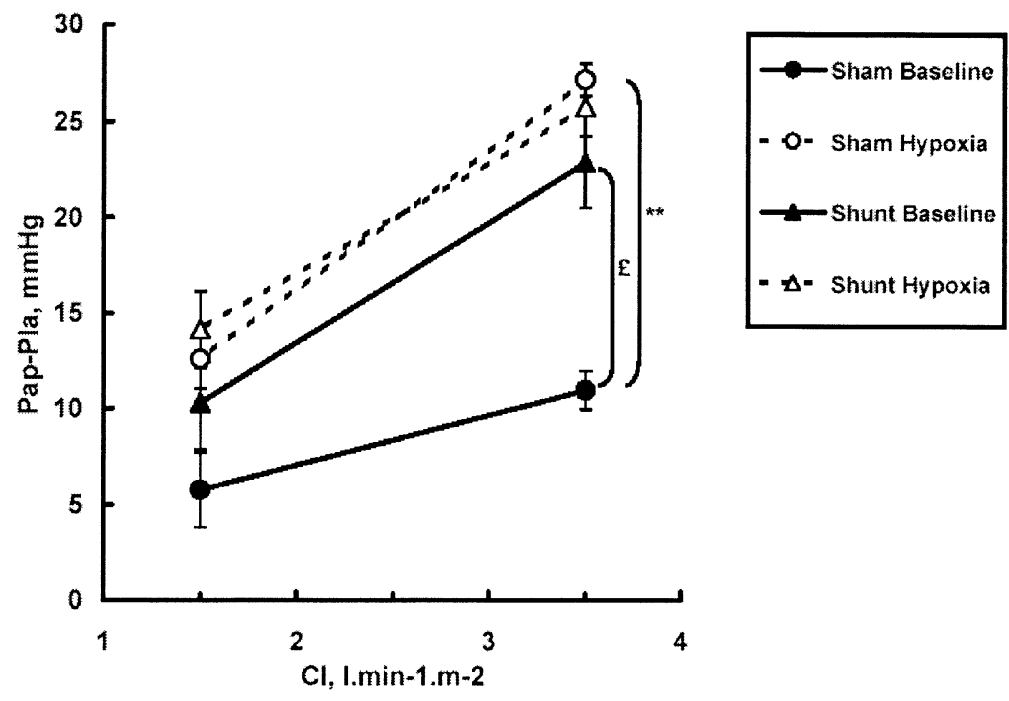

Figure 2. Composite pulmonary vascular flow pressure curves in the sham and shunt groups (means $\pm S E$ ). Effects of hypoxia: ${ }^{*} P<.01$ versus baseline, $\mathbf{f} P<.05$ versus sham. Pigs in the shunt group showed an upward shift of flow-pressure curves. Hypoxia shifted these curves upward in the sham group but not in the shunt group.

$2.5 \mathrm{~L} \cdot \min ^{-1} \cdot \mathrm{m}^{-2}$ by decreasing venous return to allow for meaningful comparisons (Tables 2-4). Compared with that in the sham group, the pulmonary circulation in animals in the shunt group was characterized by increases in Zo, Zc, and Rampl. The right ventricle showed a marked increase in afterload and in contractility (Ea and Ees). Pathologic examination showed a medial thickness of $11 \% \pm 1 \%$ in the shunt group versus $7 \% \pm 1 \%$ in the sham group $(P<.05)$. Some animals in the shunt group showed nonspecific indices of congestion (interstitial and alveolar edema, widened lymphatic vessels, and venous wall thickening). No difference was found between smaller and larger arteries in the investigated range $(80-200 \mu \mathrm{m})$.

\section{Effects of Hypoxia}

In the sham group hypoxia markedly shifted the pressureflow plots upward (Figure 2). Ppa and Ppc increased proportionally, indicating changes in both arterial and venous resistances. PVZ data showed a hypoxia-induced increase in Zo, Zc, and Rampl (Table 2). Ventricular data showed a hypoxia-induced increase in Ea and a proportional increase in Ees, resulting in a preservation of Ees/Ea. In the shunt group flow-pressure plots, PVZ data, and RV data remained unaffected by hypoxia.

\section{Effect of Prostacyclin and iNO}

Two piglets in the shunt group died from ventricular tachycardia and fibrillation when prostacyclin was increased from 2 to $4 \mathrm{ng} \cdot \mathrm{kg}^{-1} \cdot \mathrm{min}^{-1}$. Other side effects in the shunt and sham groups were premature beats in 10 pigs, hypotension in 2 pigs, and low cardiac output in $1 \mathrm{pig}$ at $18 \mathrm{ng} \cdot \mathrm{kg}^{-1}$. $\min ^{-1}$. At the time of measurement, the prostacyclin infu- sion rate was $11 \pm 2 \mathrm{ng} \cdot \mathrm{kg}^{-1} \cdot \min ^{-1}$ (range, 4-20 $\mathrm{ng} \cdot$ $\left.\mathrm{kg}^{-1} \cdot \min ^{-1}\right)$ in the sham group and $11 \pm 2 \mathrm{ng} \cdot \mathrm{kg}^{-1}$. $\min ^{-1}$ (range, 4-18 $\mathrm{ng} \cdot \mathrm{kg}^{-1} \cdot \min ^{-1}$ ) in the shunt group; for comparison, our patients with pulmonary hypertension tested for reversibility received 4 to $16 \mathrm{ng} \cdot \mathrm{kg}^{-1} \cdot \mathrm{min}^{-1}$. At baseline, prostacyclin had no effect on flow-pressure plots (Figure 3), on PVZ, or on ventriculoarterial coupling (Table 3). iNO shifted flow-pressure plots downward in both the sham and shunt groups (Figure 3 ). iNO reduced Zo, Zc, and Ees in the shunt group but not in the sham group (Table 3 ). Compared with prostacyclin, iNO reduced Zo, Zc, and Ees in the shunt group (Table 3). During hypoxia, prostacyclin somewhat shifted flow-pressure plots downward in the sham and shunt groups, whereas iNO had a more marked effect (Figure 4). At reference flow, iNO decreased Zo and Zc more than prostacyclin (Table 4). iNO decreased Ees compared with prostacyclin, but Ees/Ea was unaffected by both drugs.

\section{Discussion}

\section{Experimental Model}

Previous attempts to generate pulmonary hypertension with an aortopulmonary shunt had variable success. In utero aortopulmonary fistulas are associated with technical problems and high mortality. ${ }^{23,24}$ In young piglets Rendas and associates $^{3}$ reported more pulmonary hypertension in 4-week-old animals than in older animals. Pulmonary hypertension, however, remained moderate with 8-mm fistulas, whereas severe pulmonary edema occurred with $10-\mathrm{mm}$ fistulas. ${ }^{4}$ The present study shows that serious chronic pulmonary hypertension can be reliably caused by an aortopul- 
TABLE 2. PVZ and right ventriculoarterial coupling in piglets in the sham and shunt groups

\begin{tabular}{|c|c|c|c|c|}
\hline & \multicolumn{2}{|c|}{ Sham } & \multicolumn{2}{|c|}{ Shunt } \\
\hline & Baseline & Hypoxia & Baseline & Hypoxia \\
\hline $0, \mathrm{~L} \cdot \mathrm{min}^{-1} \cdot \mathrm{m}^{-2}$ & $2.2 \pm 0.1$ & $2.3 \pm 0.2$ & $2.4 \pm 0.1$ & $2.4 \pm 0.1$ \\
\hline $\mathrm{Ppa}, \mathrm{mm} \mathrm{Hg}$ & $16 \pm 2$ & $31 \pm 2^{*}$ & $27 \pm 1 \dagger$ & $29 \pm 1$ \\
\hline Zo, dynes $\cdot \mathrm{s}^{-1} \cdot \mathrm{cm}^{-5}$ & $600 \pm 68$ & $1087 \pm 106^{*}$ & $918 \pm 76$ & $966 \pm 96$ \\
\hline Zc, dynes $\cdot \mathrm{s}^{-1} \cdot \mathrm{cm}^{-5}$ & $64 \pm 7$ & $126 \pm 18^{*}$ & $130 \pm 16 \dagger$ & $160 \pm 12$ \\
\hline Rampl, mm Hg & $3.5 \pm 0.5$ & $5.3 \pm 0.6^{*}$ & $4.8 \pm 0.7$ & $6.9 \pm 1.4^{*}$ \\
\hline $\mathrm{Ea}, \mathrm{mm} \mathrm{Hg} / \mathrm{mL}$ & $1.3 \pm 0.2$ & $3.2 \pm 0.7^{*}$ & $2.2 \pm 0.2 \dagger$ & $2.0 \pm 0.2$ \\
\hline Ees, $\mathrm{mm} \mathrm{Hg} / \mathrm{mL}$ & $1.8 \pm 0.4$ & $4.7 \pm 0.8$ & $4.9 \pm 0.8 \dagger$ & $3.6 \pm 0.8$ \\
\hline $\mathrm{Ees} / \mathrm{Ea}$ & $1.4 \pm 0.3$ & $1.5 \pm 0.2$ & $2.2 \pm 0.3$ & $1.8 \pm 0.3$ \\
\hline
\end{tabular}

Values are means \pm SE. Ea, Effective pulmonary arterial elastance; Ees, RV end-systolic elastance; Ppa, pulmonary arterial pressure; $Q$, flow; Rampl, reflected wave amplitude; $Z c$, characteristic impedance; $Z o$, total pulmonary vascular resistance.

${ }^{*} P<.05$ versus baseline;

$\dagger P<.05$ versus sham.

TABLE 3. PVZ and right ventriculoarterial coupling: Effect of prostacyclin and iNO

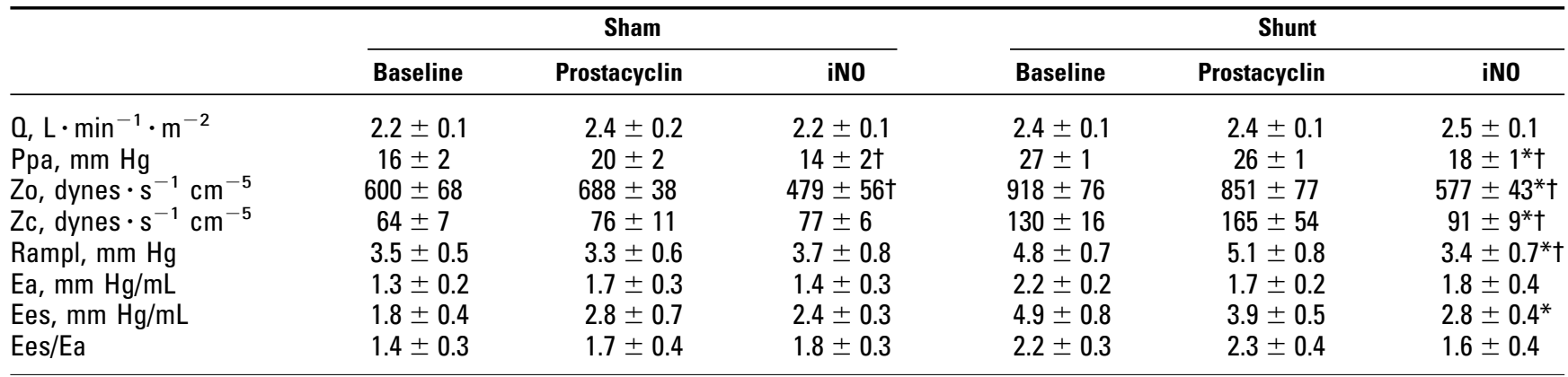

Values are means \pm SE. Ea, Effective pulmonary arterial elastance; Ees, RV end-systolic elastance; Ppa, pulmonary arterial pressure; $Q$, flow; Rampl, reflected wave amplitude; $Z c$, characteristic impedance; $Z 0$, total pulmonary vascular resistance.

${ }^{*} P<.05$ versus baseline,

† $P<.05$ versus prostacyclin.

monary shunt created with the left innominate artery in growing piglets. The surgical procedure is simple, and serious complications are uncommon because of the limited initial size of the fistula. The size of the fistula almost doubled over the 10 to 12 weeks, reaching a 9- to $10-\mathrm{mm}$ diameter that would be lethal at the time of the operation. In comparison with an 8-mm fistula, the final $20 \%$ increase in diameter represented a $44 \%$ increase in section area and a theoretic $77 \%$ decrease in resistance. This larger final shunt explains why pulmonary hypertension was more severe in our study than in previous studies. In turn, the pulmonary hypertension explains why the pulmonary/systemic flow ratio was limited to about 1.75 at the time of measurement.

\section{Pathology}

Histologic examination essentially showed medial hypertrophy of the 80- to 200- $\mu \mathrm{m}$ muscular pulmonary arteries in the shunt group. Part of this observation could be due to arterial relaxation in the absence of distending pressure during fixation. However, the difference between groups is so large $(+50 \%)$ that it is unlikely to result only from arterial retraction. Moreover, this finding is consistent with grade 1 changes reported in patients with pulmonary arterial hypertension related to congenital left-to-right shunts. ${ }^{2,25,26}$ Further stages of this type of pulmonary hypertensive vascular disease include concentric laminar intimal fibrosis, fibrinoid necrosis, dilatations, and plexiform lesions, especially in the proximal parts of the supernumerary arteries. ${ }^{25}$ Such features of advanced pulmonary hypertension were not found in our animals.

\section{Pulmonary Hemodynamics}

Most previous investigations on aortopulmonary shunts reported data collected when the shunt was patent or used pressures obtained at variable flow, so that the extent of pulmonary hypertension remained unclear. ${ }^{3,24,27}$ In studies in which data were taken after closure of the shunt and at controlled flow, pulmonary arterial pressure and resistance increased by about $25 \% .^{4,28}$ In the present study the increasing size and longer duration of the shunt resulted in an approximately $50 \%$ increase in pulmonary arterial pressure and resistance. A previous study using the double-occlusion 

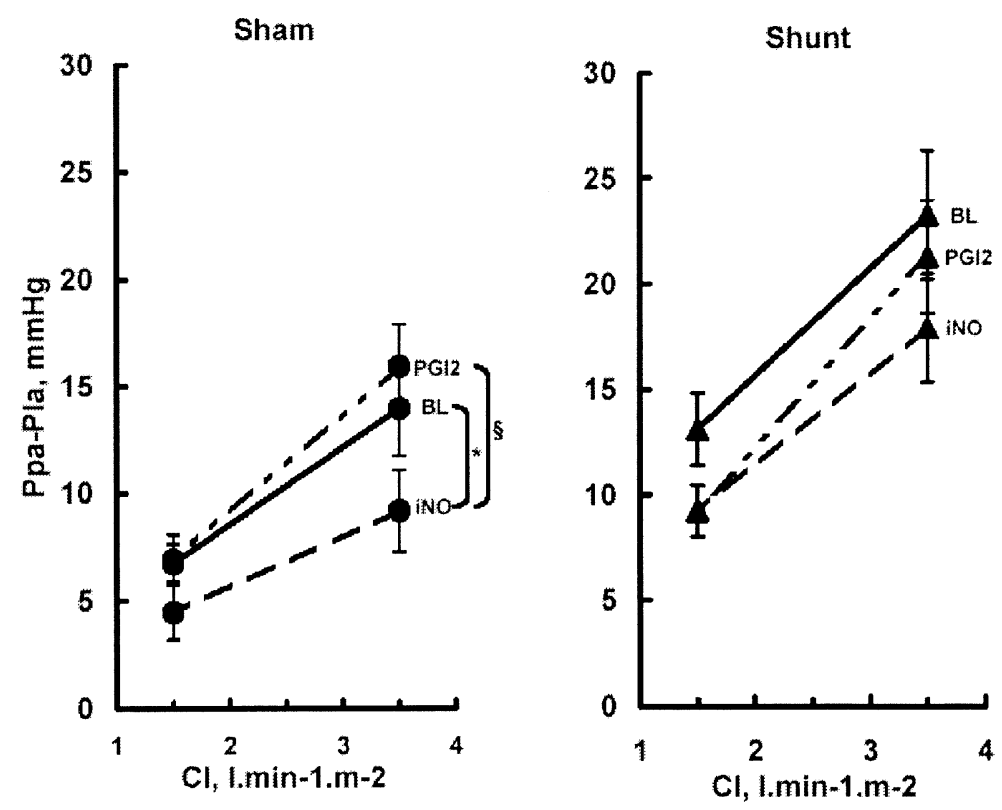

Figure 3. Effect of intravenous prostacyclin (PGI2) and iNO on pulmonary vascular flow-pressure curves in pigs in the sham and shunt groups (means $\pm \mathrm{SE}$ ). ${ }^{*} P<.05$ versus baseline $(B L), \S P<.05$ iNO versus prostacyclin. iNO shifted the curves downward in sham-treated pigs.

TABLE 4. PVZ and right ventriculoarterial coupling: Effect of prostacyclin and iNO during hypoxia

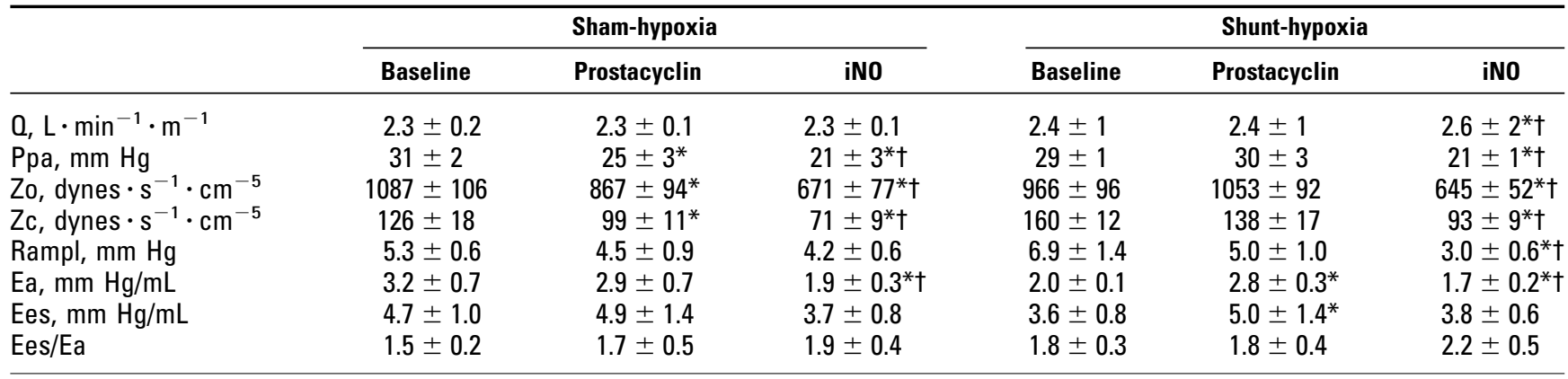

Values are means $\pm \mathrm{SE}$. Ea, Effective pulmonary arterial elastance; Ees, RV end-systolic elastance; Ppa, pulmonary arterial pressure; 0 , flow; Rampl, reflected wave amplitude; $Z c$, characteristic impedance; $Z o$, total pulmonary vascular resistance.

${ }^{*} P<.05$ versus baseline,

$\dagger P<.05$ versus prostacyclin.

method reported that a 14-month subclavian-pulmonary shunt increased arterial but not venous resistance in the shunted left lower lobe vasculature. ${ }^{27}$ We used a single occlusion method with a 3-compartment model and biexponential fitting that has been shown to yield values closest to those of the double-occlusion method. ${ }^{16}$ In the present study involving the complete pulmonary vasculature, our results show proportional increases in arterial and venous resistances, suggesting that pulmonary veins also contributed to the increased resistance. Impedance data showed normal values in the sham group ${ }^{29}$ and significant changes in the shunt group. Zo and Zc increased markedly, which is in keeping with previous observations in shunted animals ${ }^{4}$ and in children with grade I pulmonary vascular disease caused by a congenital left-to-right shunt. ${ }^{26}$ The increase in Zo reflects the upward shift of flow-pressure curves. The increase in $\mathrm{Zc}$ might be related to a decreased cross-sectional area or an increased elastance (increased stiffness and decreased compliance) of the proximal arteries. Because the proximal arteries are passively dilated in pulmonary hypertension, increased $\mathrm{Zc}$ thus indicates increased arterial elastance. Our results also show increased reflected wave amplitude, an usual consequence of increased elastance and wave velocity. Shunt-induced pulmonary hypertension was thus associated with a consistent hemodynamic picture of increased resistance of small distal vessels, increased elas- 

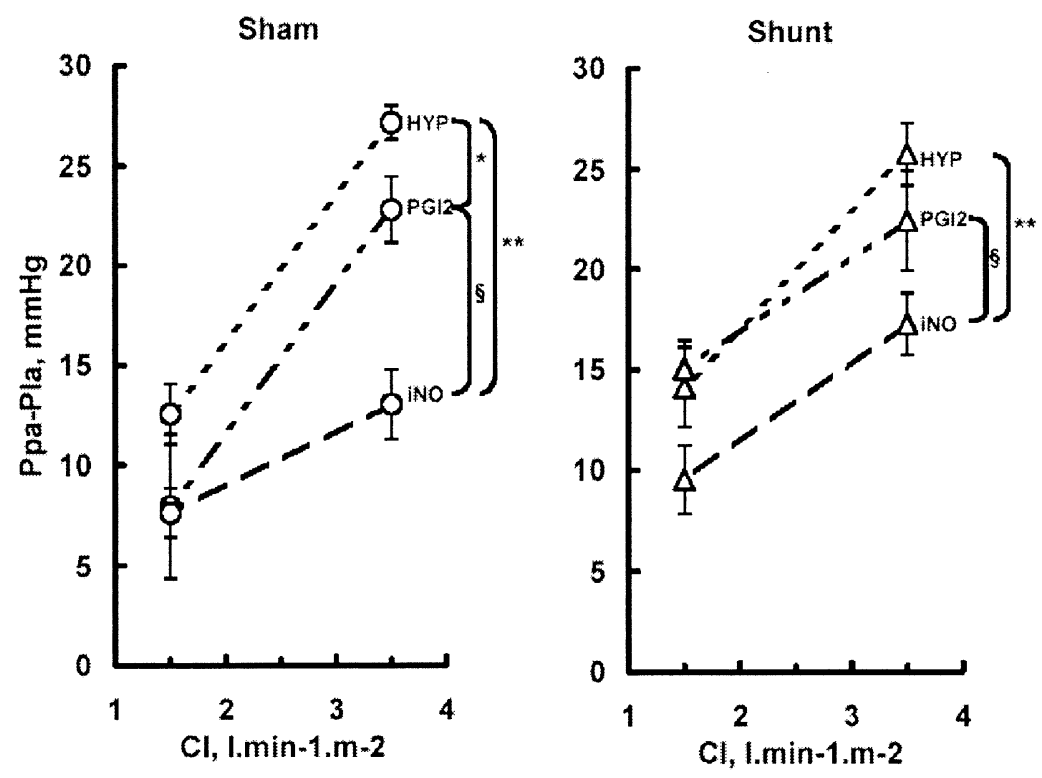

Figure 4. Effect of intravenous prostacyclin (PGI2) and iNO during hypoxia on pulmonary vascular flow-pressure curves in pigs in the sham and shunt groups (means \pm SE). ${ }^{*} P<.05$ versus baseline $(B L), \S P<.05$ versus prostacyclin. iNO shifted the curves downward more than prostacyclin.

tance of large proximal vessels, and increased amplitude of wave reflection, all of which contribute to the increase in RV afterload.

\section{RV Function}

Ees and Ea, commonly used to assess ventriculoarterial coupling for the left ventricle, can also be used for the normal right ventricle ${ }^{19}$ and for the right ventricle facing pulmonary hypertension (Wauthy and colleagues, unpublished observations). Ea integrates the major components of ventricular afterload (distal resistance, proximal elastance, and wave reflection), Ees reflects ventricular contractility, and the Ees/Ea ratio directly quantifies the ventriculoarterial coupling efficiency. Pigs in the sham group had a higher Ea than normal dogs, reflecting the natural increase in resistance and elastance of the pulmonary circulation of this species. ${ }^{29}$ Ees increased in such a way that the Ees/Ea ratio remained close to 2, the value also found in dogs and taken as optimal because it is associated with a maximal ratio between mechanical work production and oxygen consumption. ${ }^{21}$ Piglets in the shunt group had a further increase in $\mathrm{Ea}$, confirming that the shunt-induced increases in resistance and elastance resulted in an increased RV afterload. Ees again increased in such a way that Ees/Ea remained close to the optimal value of 2 . In other words, the right ventricle did adapt to match the chronically increased afterload related both to the species' features and to the chronic aortopulmonary shunt.

\section{Hypoxia}

In the sham group acute hypoxia was associated with an increase in pulmonary vascular resistance and elastance. Such effects have been reported previously and might be attributed to hypoxia itself and to the resulting adrenergic stimulation. ${ }^{15,29}$ In the shunt group the hypoxic response was significantly blunted. Previous studies reported aortopulmonary shunts both to enhance ${ }^{24}$ and to blunt ${ }^{4,30}$ hypoxic responses.

\section{Vasodilators}

Prostacyclin and NO are natural vasodilators produced by endothelial cells and acting on smooth muscle cells to maintain a low basal pulmonary vascular tone. ${ }^{10}$ Both substances have been used as potent vasodilating drugs in various states associated with pulmonary hypertension. ${ }^{8-11}$ Here, at baseline, prostacyclin had no significant effect, and iNO had only a mild vasodilating effect. These results indicate that basal pulmonary vascular tone was low because of the anesthesia, the normal blood flow and blood pressure, or both. In chronic (shunt-induced) pulmonary hypertension, prostacyclin had no effect, whereas iNO decreased resistance and elastance. In acute (hypoxic) pulmonary hypertension, whether isolated or superimposed on chronic hypertension, prostacyclin partially reversed and iNO almost completely reversed the increases in resistance and elastance. Whether in acute or chronic pulmonary hypertension, iNO was thus a better pulmonary vasodilator than prostacyclin. Ea reflected the effects of resistance, 
elastance, and wave reflections on RV afterload. Ees again increased or decreased in such a way that the ventriculoarterial coupling efficiency was maintained. This absence of change in Ees/Ea suggests that neither prostacyclin nor iNO had a specific RV inotropic effect in the present experiments.

\section{Conclusions}

We used the left innominate artery to create an aortopulmonary shunt in growing pigs that increased from 5 to 6 to 9 to $10 \mathrm{~mm}$ diameter over a period of 10 to 12 weeks. Pulmonary vascular changes were characterized by medial hypertrophy of small arteries and a corresponding increase in resistance, elastance, and wave reflection. RV contractility increased to match the increased afterload, thus preserving ventriculoarterial coupling efficiency. iNO reversed both chronic (shunt-induced) and acute (hypoxic) pulmonary hypertension better than prostacyclin. Neither drug had a specific inotropic effect.

C. Mélot, MD, PhD, MScBiostat, reviewed the statistical methods.

\section{References}

1. Stark J, de Leval M. Surgery for congenital heart defects. 2nd ed. Philadelphia: W.B. Saunders; 1994.

2. Harris P, Heath D. The human pulmonary circulation. Edinburg: Churchill Livingstone; 1977.

3. Rendas A, Lennox S, Reid L. Aorta-pulmonary shunts in growing pigs. Functional and structural assessment of the changes in the pulmonary circulation. J Thorac Cardiovasc Surg. 1979;77:109-18.

4. De Canniere D, Stefanidis C, Brimioulle S, Naeije R. Effects of a chronic aortopulmonary shunt on pulmonary hemodynamics in piglets. J Appl Physiol. 1994;77:1591-6.

5. Turanlahti MI, Laitinen PO, Sarna SJ, Pesonen E. Nitric oxide, oxygen, and prostacyclin in children with pulmonary hypertension. Heart. 1998;79:169-74.

6. Hoeper MM, Olschewski H, Ghofrani HA, Wilkens H, Winkler J, Borst MM, et al. A comparison of the acute hemodynamic effects of inhaled nitric oxide and aerosolized iloprost in primary pulmonary hypertension. German PPH study group. J Am Coll Cardiol. 2000;35: 176-82.

7. Sitbon O, Brenot F, Denjean A, Bergeron A, Parent F, Azarian R, et al. Inhaled nitric oxide as a screening vasodilator agent in primary pulmonary hypertension. A dose-response study and comparison with prostacyclin. Am J Respir Crit Care Med. 1995;151:384-9.

8. Montalescot G, Drobinski G, Meurin P, Maclouf J, Sotirov I, Philippe $\mathrm{F}$, et al. Effects of prostacyclin on the pulmonary vascular tone and cardiac contractility of patients with pulmonary hypertension secondary to end-stage heart failure. Am J Cardiol. 1998;82:749-55.

9. Rich S, McLaughlin VV. The effects of chronic prostacyclin therapy on cardiac output and symptoms in primary pulmonary hypertension. J Am Coll Cardiol. 1999;34:1184-7.

10. Goldman AP, Delius RE, Deanfield JE, Macrae DJ. Nitric oxide is superior to prostacyclin for pulmonary hypertension after cardiac operations. Ann Thorac Surg. 1995;60:300-5.

11. Day RW, Hawkins JA, McGough EC, Crezee KL, Orsmond GS. Randomized controlled study of inhaled nitric oxide after operation for congenital heart disease. Ann Thorac Surg. 2000;69:1907-12.

12. Schulze-Neick I, Bultmann M, Werner H, Gamillscheg A, Vogel M, Berger F, et al. Right ventricular function in patients treated with inhaled nitric oxide after cardiac surgery for congenital heart disease in newborns and children. Am J Cardiol. 1997;80:360-3.

13. Loh E, Stamler JS, Hare JM, Loscalzo J, Colucci WS. Cardiovascular effects of inhaled nitric oxide in patients with left ventricular dysfunction. Circulation. 1994;90:2780-5.

14. Semigran MJ, Cockrill BA, Kacmarek R, Thompson BT, Zapol WM, Dec GW, et al. Hemodynamic effects of inhaled nitric oxide in heart failure. J Am Coll Cardiol. 1994;24:982-8.

15. Brimioulle S, Maggiorini M, Stephanazzi J, Vermeulen F, Lejeune P, Naeije R. Effects of low flow on pulmonary vascular flow-pressure curves and pulmonary vascular impedance. Cardiovasc Res. 1999;42: 183-92.

16. Baconnier PF, Eberhard A, Grimbert FA. Theoretical analysis of occlusion techniques for measuring pulmonary capillary pressure. J Appl Physiol. 1992;73:1351-9.

17. Bergel DH, Milnor WR. Pulmonary vascular impedance in the dog. Circ Res. 1965;16:401-15.

18. Fitzpatrick JM, Grant BJ. Effects of pulmonary vascular obstruction on right ventricular afterload. Am Rev Respir Dis. 1990;141:944-52.

19. Brimioulle S, Wauthy P, Ewalenko P, Rondelet B, Vermeulen F, Kerbaul F, et al. Single-beat estimation of right ventricular endsystolic pressure-volume relationship. Am J Physiol Heart Circ Physiol. 2003;284:H1625-30.

20. Maughan WL, Shoukas AA, Sagawa K, Weisfeldt ML. Instantaneous pressure-volume relationship of the canine right ventricle. Circ Res. 1979;44:309-15.

21. Burkhoff D, Sagawa K. Ventricular efficiency predicted by an analytical model. Am J Physiol. 1986;250:R1021-7.

22. Wagenvoort CA. Lung biopsy specimens in the evaluation of pulmonary vascular disease. Chest. 1980;77:614-25.

23. Black SM, Fineman JR, Steinhorn RH, Bristow J, Soifer SJ. Increased endothelial NOS in lambs with increased pulmonary blood flow and pulmonary hypertension. Am J Physiol. 1998;275:H1643-51.

24. Reddy VM, Meyrick B, Wong J, Khoor A, Liddicoat JR, Hanley FL, et al. In utero placement of aortopulmonary shunts. A model of postnatal pulmonary hypertension with increased pulmonary blood flow in lambs. Circulation. 1995;92:606-13.

25. Heath D, Edwards JE. The pathology of the hypertensive pulmonary vascular disease. A description of six grades of structural changes in the pulmonary arteries with special reference to congenital cardiac septal defects. Circulation. 1958;18:533-47.

26. Wilcox BR, Lucas CL. Pulmonary input impedance in children with left-right shunt. J Surg Res. 1980;29:40-9.

27. Michel RP, Hakim TS, Hanson RE, Dobell AR, Keith F, Drinkwater D. Distribution of lung vascular resistance after chronic systemic-topulmonary shunts. Am J Physiol. 1985;249:H1106-13.

28. Hopkins RA, Hammon JW, McHale PA, Smith PK, Anderson RW. Pulmonary vascular impedance analysis of adaptation to chronically elevated blood flow in the awake dog. Circ Res. 1979;45:267-74.

29. Maggiorini M, Brimioulle S, De Canniere D, Delcroix M, Wauthy P, Naeije R. Pulmonary vascular impedance response to hypoxia in dogs and minipigs: effects of inhaled nitric oxide. J Appl Physiol. 1995;79: 1156-62.

30. Bousamra M 2nd, Rossi R, Jacobs E, Parviz M, Busch C, Nelin LD, et al. Systemic lobar shunting induces advanced pulmonary vasculopathy. J Thorac Cardiovasc Surg. 2000;120:88-98. 